\title{
Adaptive Management in Fire Regulation and Emergency Response
}

\author{
BRIAN MEACHAM, ${ }^{*}$ JOSEPH SARKIS ${ }^{+}$and NICHOLAS DEMBSEY* \\ *Department of Fire Protection Engineering, WPI, 100 Institute Road, Worcester, MA, 01609 \\ ${ }^{+}$Graduate School of Management, Clark University, 950 Main Street, Worcester, MA, 01610
}

\begin{abstract}
Adaptive management comes from the study of complex adaptive systems. Concepts of adaptive management have begun to be considered for disaster mitigation and emergency response. It is suggested that fire in buildings is a complex adaptive system, and therefore subject to adaptive management techniques. This paper outlines criteria that can be used to test the applicability of adaptive management concepts to various regulatory, emergency planning and mitigation issues, with an exemplar application of the criteria to challenges of fire regulation, protection and emergency response planning for buildings.
\end{abstract}

KEYWORDS: performance-based codes, emergency response, adaptive management

\section{INTRODUCTION}

The terrorist attacks of September 2001 and the impacts of Hurricane Katrina in September 2005 reveal that existing approaches to extreme event disaster prevention, mitigation and emergency response in the United States are lacking, and as a result, significant impacts on people, property and the economy have been realized. Although the events were much different, a number of common characteristics were evident:

- Low probability, high consequence events, for which neither appropriate mitigation nor emergency response systems were in place,

- Initial confusion amongst those responsible for emergency response,

- Inadequate emergency response in the critical, early stages of the event, and

- An apparent desire to follow procedures without accounting for event-specific considerations.

Given the extreme nature of the events, it could be argued that the level of regulation, lack of mitigation planning and response preparedness, and poor response execution, resulted from a societal view that the likelihood of extreme event occurrence was sufficiently low that the risk was tolerable, and therefore the impact and response were commensurate with the level of risk perceived and the level of funding provided. As such, unless society changes its perception of the risks, there is no need to change the approach to regulation, mitigation or response. However, it can also be argued that since extreme events are unpredictable, characterized by a high degree of uncertainty and variability, and have the potential for catastrophic impacts, more robust measures should be implemented regardless of cost. This 'precautionary principle' approach might help to mitigate impacts, but would come at a high cost.

In reality, neither of the above views leads to viable solutions on their own: catastrophic losses are not tolerable, yet resources are limited. These factors and more were observed by McConnell and Drennan [1] who identified four major issues that define the difficulties associated with emergency planning: crises and disasters are low probability events, but they place large demands on resources; emergency planning requires ordering and coherence of possible threats, yet these events are difficult to package in such a predictable way; planning for crises requires integration and synergy across institutional networks, but fragmentation across public, private and voluntary sectors exists; and robust planning requires active preparation through training and exercises, but such costly activities are usually symbolic. The challenge is that any model of emergency management has 'planning' and 'preparing for a crisis' as core elements, yet emergency situations have high uncertainty in terms of 'when' and 'where.' Planning, if it is to work, must be made in such a way that it is adaptive and learns.

As a means to address these challenges and to facilitate more cost-effective and robust approaches for extreme event mitigation and emergency response planning, we suggest that application of adaptive management concepts may provide an appropriate framework for some types of events. To test which events are conducive to adaptive management concepts, a set of criteria has been postulated and applied to various events, including fire. 


\section{ADAPTIVE MANAGEMENT CONCEPTS}

The basis for adaptive management comes from the study of complex adaptive systems (CAS), which Holland [2, 3] describes as systems involving self-organizing behavior, where the agents involved can adapt their actions to changes in their environment based on observation or incoming information. Similarly, Comfort [4] describes CAS as systems in which agents can search for and share information, which they can then use to adapt their behavior, and Plsek et al. [5] define them as systems of individual agents, who have the freedom to act in ways that are not always totally predictable, and whose actions are interconnected such that one agent's actions changes the context for other agents. Central to each of these definitions are the presence of agents, who can learn and adapt, and in doing so influence or change the system. As described by Dooley [6], these agents are semi-autonomous units that seek to maximize some measure of goodness, or fitness, by evolving over time.

The concept of adaptive management builds upon the premise that agents can learn and adapt in complex environments, and suggests therefore that management policies should not be assumed to be rigid or fixed for all time, but should be designed to learn and adapt. Lee [7] has expressed the view that an adaptive management approach treats policies as experiments, recognizing that unanticipated outcomes are inevitable, and that they present opportunities for learning, which should be fed back into the policies. Bennett and Lawrence [8] have described adaptive management as a systematic process for continually improving management policies and practices by learning from the outcomes of operational programs. The need to incorporate agents who can help in the learning and adapting process from multidimensional perspectives has also been noted $[9,10]$. More detailed descriptions or lists of attributes that form the basis of complex adaptive systems and adaptive management have also been developed (e.g., see [5, 11]).

Understanding how systems adapt is also necessary. Carley [12] suggests that one type of adaptation is reactive, which involves rapid change to a rapidly changing environment (e.g., teams are often adaptive in the short term due to a re-active strategy), with another being proactive, which is designed to minimize the chance of error cascades. Comfort [13], using different terminology, identifies four types of adaptive systems: non adaptive, emergent adaptive, operative adaptive and auto-adaptive systems.

\section{Adaptive Management and Protection of People in Emergency Situations: Existing Work}

In the context of terrorism, Comfort [4] suggests the theoretical model of CAS offers an alternative model for governmental action in coping with terrorism, instead of relying on the traditional hierarchical reporting, command and control communication relationship. The view is expanded upon in a related paper, where Comfort [13] notes that "one of the challenges in disaster planning is how to design and support governmental systems that can adapt readily to the urgent demands and complex operating conditions in extreme events. A hierarchical approach almost always fails. In extreme events, public organizations need the ability to adapt quickly and effectively to rapidly changing conditions. Such capacity relies on a continuous exchange of timely, valid information among multiple participants regarding their shared goal in dynamic operating conditions. Relations between organizations and their operating conditions are nonlinear, and actions must be based on incoming information integrated with known information to adapt effectively to the changing environment."

To improve intergovernmental performance and coordination in response to extreme events, Comfort [13] suggests that auto-adaptation is appropriate. For threats of unbounded uncertainty, such as terrorism or other extreme events, an auto-adaptive system that is able to learn from incoming information, reallocate its resources and attention, reorder its relationships with other entities, and act promptly to reduce the threat or respond to destructive acts is the most appropriate approach. Comfort describes the five phases of autoadaptation as: 1) information search or scanning, 2) information exchange, 3) sense making, or selection of a plausible strategy of action, given the situation and resources available, 4) adaptation, or action taken to implement that strategy, and 5) evaluation of actions taken and modification of succeeding actions on the basis of observed results. Focusing on a somewhat different area of emergency response, Perry and Lindell [14] suggest that emergency response managers should take into consideration basic behavioral principles. They list the following suggestions: address public fears as soon as an incident has taken place by disseminating information about the hazard and recommended protective actions, expect citizens to take action, and expect compliance from citizens, particularly when a geographically defined scene is present and disaster onset is rapid. 


\section{THE CRS CRITERIA FOR APPLICABILITY OF ADAPTIVE MANAGEMENT CONCEPTS}

In considering various perspectives on CAS and adaptive management, researchers at the Center for Risk and Security (CRS) at Clark University suggest that adaptive management concepts may be well suited to some, but not all, types of disaster mitigation and emergency response planning and implementation [15], and that the following list of key assumptions, goals and features can be useful in determining suitability for adaptive approaches:

A. Assumptions - These are characteristics that of the emergency situations and crises (seen and unforeseen) that will be underlying the development of goals and necessary features.

1. The problem has characteristics of adaptive systems, including high uncertainty and decision stakes.

2. Rational but oft ill-informed publics - The public will not typically panic in unforeseen circumstances and will tend to act rationally, but their actions will be subject to the most current and identifiable information. Thus, ill-informed people will tend to make sub-optimal decisions.

3. Emergent, self-organizing groups - In most emergency situations, groups with official authority (first responders, trained emergency personnel) will not be available during the early moments. Thus, emergent leaders and groups forming on their own without official capacity may be the first respondents in a crisis.

4. Social networks important - The use of informal networks will prove very valuable in moments of crisis. The relationships that individuals and organizations have will prove critical in managing information, material and supplies, among other resources.

5. Institutional fragmentation - It is expected that the official institutions with resources, knowledge and power, will not be easily identifiable nor accessible during moments of crisis.

B. Goals - the following will be goals of research and practice for adaptive management in regulation, mitigation, and emergency planning and response.

1. High social learning, during and between events - High social learning is a necessary goal such that knowledge is effectively administered to potentially effected populations. This learning may necessarily become instinctual such that learning cannot be forgotten. Unpredictable crises can occur at any time and in varying frequencies. Higher level learning means that the knowledge becomes ingrained in various societal actors and institutions.

2. Broad contingency planning - The breadth of contingency planning for emergency response should not only rest on the shoulders of official responders. As noted in the previous assumptions, institutional fragmentation and emergent self-organizing groups will necessarily occur. Thus, contingency planning aimed at broader groups for emergency response, through various channels should be a goal if effective response is to be considered. The adaptation of regulation and of the public will be necessary in this situation.

3. Evolutionary sequential coping - Adaptation requires building on the knowledge of previous situations and experimenting the successes and failures of various policies and practices. An adaptive system needs to evolve temporally to effectively aid in social and institutional learning at all levels.

4. High management flexibility and rapid response - Adaptation requires that management reporting systems and 'bureaucracies' are flexible enough so that lines of communication and flows of information and resources are not effected due to inflexible management and reporting systems. This management flexibility is necessary for rapid response. Taking advantage and supporting emergent leaders and self-organizing groups and allowing for their inclusion in a management structure should be part of any adaptive management model.

5. Exploit fully existing response capabilities - This goal pertains to eliminating 'the reinvention of the wheel'. There are currently many channels for emergency planning and response management. Determining linkages and synergies between these channels and resources needs to be evaluated and completed. 
6. Sustain and build anticipatory and response capabilities - The acknowledgement that although emergency events are highly uncertain events, there are response needs that can be planned for in anticipation of the events. Identifying gaps and limitations of the current capabilities, structures, and resources is an important goal. Effectively defining where resources should be allocated will be part of this process.

C. Features - represent characteristics for adaptive management systems that will further help attain the goals, essentially forming strategies for organizations to follow and researchers to investigate.

1. Real-time monitoring - Monitoring of events will be necessary for rapid feedback to various situations. Tools such as 'sensor-nets' and various emergent information and communication technology (ranging from cell phones to mobile commerce capabilities) are expected to play a large role in an adaptive management environment.

2. Contingency planning - Even though adaptive management is based on being able to react and learn from experimental events using various agents, the role of planning is still required. This planning needs to determine the most effective designs and implement and study them.

3. Dense communication and information environments - The roles of communication and information networks will be critical in not only disseminating knowledge during a crisis but also in preparation and management of that crisis after it occurs. Density of communication means taking advantage of various networks (formal and informal) and technologies. Building redundancies is necessary since in most adaptive crises situations, ill-informed publics can act rationally only if information is easily and repeatedly accessible.

4. Open management systems - these systems require easy access and quick relationships among various management structures and institutions to occur.

5. Uncertainty and error acknowledgement - Understanding various probability schemes and learning from errors is critical to managing and improving the knowledge. Understanding and acknowledging the various environmental uncertainties and risks can provide rational for various decisions. Tools and models need to explicitly integrate and acknowledge these imperfections in information and outcomes.

6. Bottom-up and top-down planning - Information flow and planning need both directions for effective adaptive management environments. Knowledge can flow in many directions. Effectively supporting this type of planning allows stakeholders at all levels to fully understand, learn and contribute to the improvement of adaptive management systems.

These are initial categories and issues facing adaptive environments. Thus, these are theoretical and conceptual issues that need validation and refinement. Additions, changes or deletions should be identified in the process as a means to advance the test for appropriateness.

\section{Understanding the Environment: Situation, Actors, Structures, Information and Decision-Making}

Before applying the CRS criteria, it is suggested that additional factors should also be considered. Specifically, one needs to understand the environment within which the management approach will be developed and implemented. This includes such factors as the situation(s) requiring action, what actors (agencies, organizations, institutions and individuals) are involved and how they operate, the interrelationships between the actors, the relationships and structures are within agencies, organizations and institutions, information availability and goodness, and decision-making processes in use or available for use. These factors are important in that they help to assess whether adaptive or non-adaptive approaches make sense or not, and what infrastructure is required to make adaptive approaches successful.

In some cases, it may be better to have a very hierarchical management structure, where each step is well defined, and modification or adaptation is not encouraged. Consider traffic lights and stop signs. These safety features were implemented to minimize accidents at intersections and to optimize traffic flow, as allowing every driver to make their own decision could result in more accidents. In this case, rigid structure is helpful for making intersections safer. It approach works not only because of traffic lights and stop signs, but because of law enforcement, insurance premiums for causing accidents, the fear of jail time, and related institutional and economic pressures and influences. 
By contrast, consider pricing of merchandise in a store. If ill-informed staff members are allowed to set prices, in the absence of proper guidelines and data, it is possible that the store could be bankrupt in a very short time. However, if data are available, staff could make short-term decisions that could result in increased revenue. In this case, the key to whether or not an adaptive approach makes sense is contingent on the availability of information (on the market, the customers, the cost of doing business, required profit margins, etc.). If the necessary information cannot (or will not) be made available, implementation of an adaptive approach could be catastrophic. However, if all (or enough) of the needed information is available, an adaptive approach could result in greater sales and profits.

Another factor to consider is establishing systems and undertaking training that gets people to focus on outcomes rather than on processes. A balance needs to be struck between giving guidance and prescribing actions. One can almost be assured that the event that occurs will not mirror the event planned for. It is much more important to understand what outcomes are desired, and how to assess options to get there, rather than following a plan that, in some cases, could exacerbate the problem (e.g., if the plan is to exit a building by the stairs, and the stairway is full of smoke, it may not be appropriate to go down the stairs).

Other factors include information availability and the decision-making process. These go hand-in-hand. In a system that allows for adapting based on available information, the more credible information that is available, the more informed the decision can be. However, the goodness of the decision will also depend on who the decision-makers are, what processes they use, and what alternatives are available. Various issues need to be considered, including how much information is enough or too much (information overload), and what boundaries around the decision-making process can help in assessing the situation and taking appropriate action, without being overloaded with alternatives (analysis paralysis).

\section{A View on Adaptive Management for Disaster Mitigation and Emergency Response}

A fundamental basis for the view that adaptive management concepts can be effective for disaster mitigation and emergency response is the assertion that one cannot develop disaster mitigation and emergency response plans or policies which can a priori anticipate all possible events, and therefore, the plans and policies should be structured in such as way so as to learn from actual events as they occur, or within a reasonable time after the event, and adapt appropriately. In other words, plans and policies should not be written in the form of a linear process that must be followed in a precise order, without room for modification, but should be presented in a manner that allows feedback from actual events to influence emergency management process in the short term, and the disaster mitigation policies in the longer term. This structure does not mean that all policies and procedures need to be completely flexible, but rather, should be structured in such as way that they can be 'self-learning,' allowing for adjustments as new and pertinent information becomes available. Likewise, the institutions involved need to take an adaptive approach, or at least be open to the use of adaptive approaches. Otherwise, the policies, plans and people will likely not be adaptive, or not be allowed to adapt, as events unfold.

Adaptive approaches make sense for disaster mitigation and emergency response because the situations are complex and adaptive, changing with time, agent, and agent influences, are highly uncertain and challenging to predict (at least for some critical details), and the ultimate effectiveness is driven by actions taken by agents during events. It could be argued that one way to test for whether adaptive management concepts are be appropriate may be to apply the concepts of Funtowicz and Ravetz [16] in terms of the degree of system uncertainty and decision stakes (see Figure 1). In brief, when both the decision stakes and the system's uncertainty are low, problem solving approaches normally associated with applied science (or in this case, hierarchical plans and policies) are appropriate. As both the decision stakes and the systems uncertainties increase, there is a transition to consultant-based problem solving, where more than a pure scientific approach (or hierarchical structures) may be necessary and appropriate. In these cases, there are typically conflicting values and a variety of technical options that must be balanced using a combination of scientific knowledge, judgment and experience. When both the decision stakes and the systems uncertainties are high, more is required to solve problems effectively than applied science or professional expertise (or following highly prescriptive, linear plans) alone. These situations are typically ones where facts are uncertain, values are in dispute, stakes are high and decisions are urgent. In these cases, input from the concerned public and other stakeholders is needed in addition to applied science and professional consultancy (for mitigation policy development), and the ability to react quickly to feedback from agents is needed for effective emergency response. 


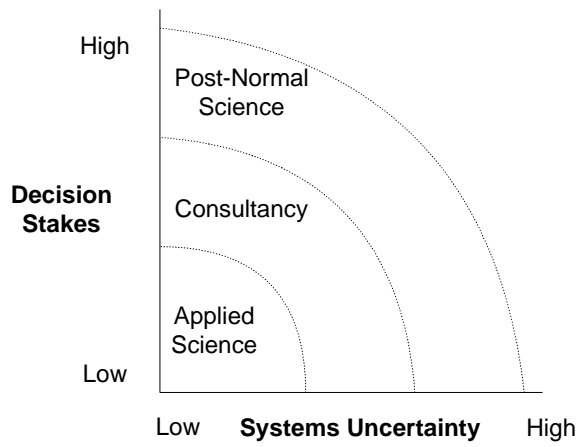

Fig. 1. Problem solving categorization based on event uncertainty and decision stakes level.

A conceptual generic risk model to follow in the development of adaptive approaches to disaster mitigation policies and emergency response plans is that outlined by the National Academies in the 1996 text (see Figure 2), Understanding Risk: Informing Decisions in a Democratic Society [17]. Although the focus on text was on risk characterization, the foundational concept, the analytic-deliberative process, appears ideally suited as a model for adaptive management due to its multiple ingrained learning and feedback mechanisms and diagnosis of results and possible experimentations.

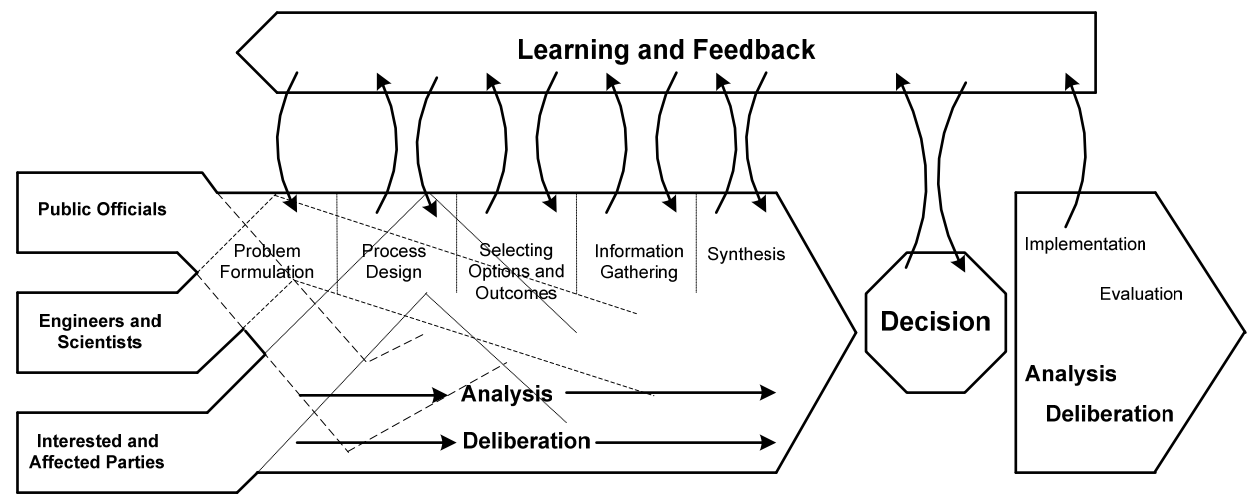

Fig. 2. Generic Adaptive Management Risk Characterization Analysis Model with Learning and Feedback

Good risk characterization depends on systematic analysis that is appropriate to the problem, responds to the needs of the interested and affected parties, and treats uncertainties of importance to the decision problem in a comprehensible way. Success depends on deliberations that formulate the decision problem, guide analysis to improve decision participants' understanding, seek the meaning of analytic findings and uncertainties, and improve the ability of interested and affected parties to participate effectively in the risk decision process. Key to the process is the ongoing feedback into the deliberation and decision processes. The applicability of risk characterization to building fire safety regulation has been discussed elsewhere $[18,19,20]$.

\section{ADAPTIVE MANAGEMENT IN FIRE REGULATION AND EMERGENCY RESPONSE}

As a case example, we have considered the case of planning, policy, design and response to extreme fire events in buildings by applying the CRS adaptive management criteria to the fire safety problem.

\section{Assumptions}

Fire safety regulation, design and response have high systems uncertainty and decision stakes, and the entire process can be characterized as a complex adaptive system. Fire development and spread is highly uncertain and difficult to accurately predict, primarily because people can change the severity and consequences of a fire (change contents, leave doors open allowing increased ventilation to fire or greater distribution of smoke, stay when one should leave, leave when one should stay, etc). This makes regulation, design and response difficult outside of an adaptive framework. 
The understanding of fire development and the onset of untenable conditions in a small, well-defined compartment are scientifically well known. (At least relatively well-known if one knows the compartment materials, geometry, ventilation characteristics and fuel characteristics, arrangement and amount.) For the modeling of a laboratory test within the compartment with the pertinent factors being known, the systems uncertainties and decision stakes are low. This example is applied fire science. If one attempts to model a fire in a non-laboratory environment, such as for the design of fire protection systems for a single compartment in an office building (e.g., a computer room), both the system's uncertainty and the decision stakes increase, requiring expert judgment and experience to bridge gaps between scientific facts, client desires, loss potentials, and unknowns. This is a classic example of where fire protection engineering consultants are used. If one then wants to model fire initiation, development and spread throughout an entire building - with the significant uncertainty and unknowns associated with human behavior and changes to the building, and the significant life or death implications of fire safety decisions - it can be argued that the realm of post-normal science has been reached. This situation is especially true for very large buildings with large numbers of occupants, wherein a severe fire can have catastrophic consequences.

The uncertainty and decision stakes become even higher when one factors in emergency response. When emergency responders arrive on scene, they have limited information about the possible fire development and the status of building occupants, but they must make critical emergency management decisions on-site, adapting to the data which are available. In the case of the attacks on the World Trade Center, there was conflicting information given to occupants of Tower 2 regarding whether to stay in place or evacuate, resulting in a delay in occupant evacuation, and the response to fires in both towers resulted in hundreds of responders being in the buildings when they collapsed [21]. In extreme fire situations the interaction between fire impacting building occupants, occupants impacting the fire and the responders, and responders impact the occupants and building, results in a complex adaptive system.

Rational but ill-informed public. Because the likelihood of fire is perceived to be low - in part due to the actual number of fires per year, but also to how fire is portrayed in television shows and in movies - the public is generally ill-informed as to how severe, lethal or fast-developing a fire can be (the Station nightclub went from "no fire" to "fully involved in fire" within about a minute [22]), or how they can contribute the fire's severity, or just how much their own safety relies on their actions (the simple act of leaving a door open can make the difference in a fire that self terminates in the room of origin, and one that destroys an entire building). There is also a perception that fire risk is higher in high-rise buildings than in the home. However, high-rise office buildings have multiple fire protection measures and very few fire deaths on an annual basis, while more than $80 \%$ of fire deaths occur in residential occupancies [23].

Emergent, self-organizing groups. The concept of emergent norm theory has been reviewed in the context of emergency evacuation and response [24, 25]. A fire can create a sense of uncertainty and urgency which forces people to act, and in the lack of clear information, instruction or leadership, participants are forced to create a new, emergent normative structure to guide their behavior, thus adapting to the situation at hand. Many aspects of emergent, self-organizing groups were observed in the 2001 attack on the World Trade Center, ranging from decisions by some to evacuate from Tower 2 even though they were advised to stay in place (someone decides to leave, and becomes a de facto leader of others), to others assisting physically disabled persons during the evacuation, even if they were not responsible or trained [26].

Social networks important. In a home, family members often put themselves at risk to save other family members. In office buildings, reactions range from management directing people not to evacuate, to people staying behind to assist those with disabilities (as in the World Trade Center attacks in 2001, for example) $[21,26,27,28]$.

Institutional fragmentation. Building fire safety and emergency response is impacted by numerous institutions which can be highly fragmented and sometime incompatible. There are building codes, fire codes, installation, test and maintenance standards, insurance requirements, fire fighting procedures, and evacuation procedures, for a start. Organizations responsible for implementation of measures range from building designers, to owners and managers, tenants, the Building Department, the Fire Department, and so forth. As a result, the building fire safety system and response strategy may vary greatly from building to building, which imposes a significant challenge on emergency responders. This was observed in the response to the World Trade Center attacks, where the multiplicity of responding agencies, without a clear chain of command and cohesion, resulted in initial confusion [21]. 


\section{Goals}

High level of social learning, during and between events. Building fire regulations and emergency evacuation and response systems have and will rely on a significant level of social learning during and between events. Consider evacuation from a high-rise building. For decades people have been told to avoid elevators in a fire and to use the stairs. Through social learning, the result is that people will not stand in an elevator lobby and wait for the elevator, but will evacuate using the stairs. However, as buildings get taller, there is a move to incorporate elevators into standard evacuation plans. For this integration to work, we will be asking people to change their behavior. This will require more than simply changing the regulation, it will involve training and education through drills and other mechanisms, and people will have to learn that it is ok to use elevators during a fire (in some cases). This requires an adaptive approach.

Likewise, during events occupants evacuating a building necessarily adapt to the information available, be it in terms of fire cues, communication or direction provided by managers or emergency responders, and the response of others. Since all fire events are different, occupants need to learn from the information and adjust accordingly. For example, there are fixed numbers and locations of exit stairs, but building occupants cannot know in advance where a fire will start, if a particular path of egress will be blocked, and where exactly they should go. When an alarm sounds, occupants have to take stock of the situation and adapt as needed. An evacuation plan that is too prescribed, and that does not take into account real time information, could have problems. The same is true with respect to emergency response. Because the exact nature of a fire will not be known until responders arrive on the scene, the entire emergency response process needs to be adaptive. Having a set of steps to execute upon arrival at a scene is helpful in initiating the response, but from that point forward, the actual response needs to adapt to the specifics of the event.

Between events, the fire regulation system is adaptive in the sense that code changes are made each time there is a major fire event. However, prescriptive codes provide general guidance for classes of buildings, rather than individual buildings, so the adaptive nature is somewhat limited, and more can be done with a transition to a risk-informed performance-based approach. In brief, the concept of a risk-informed performance-based approach is to establish regulations and design methods that focus more on desired outcomes, rather than on prescribed features (for more information, see, for example, $[29,30]$ ). The riskinformed performance-based approach is adaptive, in the sense that each building is required to be assessed for a wide range of potential fire scenarios, and fire protection systems and strategies are selected based on a combination of factors, including occupant risk factors, a wide range of possible fire scenarios, and expected emergency response. The approach should include identification and treatment of uncertainty and variability as part of the assessment and mitigation design. With the transition to risk-informed performance-based regulation and design, emergency response would need to become more adaptive and become broader in scope. For example, in a prescriptive system, the emergency responders could assume a building had certain features, as it would have been designed to the code. Under a risk-informed performance-based system, each building will likely be different, even within the same class. Because emergency response depends on features in buildings, and performance based design means not all buildings have the same features, emergency response therefore needs to be adaptive.

Broad contingency planning. As discussed above, it is not possible to precisely identify and plan for every type of fire emergency in advance, and there is some reliance on building occupants to adapt as the event develops. To help building occupants adapt quickly, however, evacuation plans which address a broad range of event types and suitable responses can be implemented. There exist standards to help with such broad contingency planning with respect to fire, such as NFPA 1600, Standard on Disaster/Emergency Management and Business Continuity Programs [31], as well as texts on egress and evacuation planning for buildings (e.g., [26]). These documents stress the need for emergency response planning to be broadbased, including building management, tenants and emergency responders.

Evolutionary sequential coping. Building fire safety regulation and emergency response planning has been an evolutionary process, with changes to regulation coming as a direct result of unacceptable fire impacts. Recent examples include requirements for fire sprinklers in nightclubs (following the Station nightclub fire in Rhode Island), with various requirements for exits dating to tragic fires in the first half of the $20^{\text {th }}$ century (e.g., the Cocoanut Grove nightclub fire and the Triangle Shirtwaist factory fire), and others dating to the fire of London in 1666 (fire separation between buildings) [26]. Building fire safety regulation and emergency response planning needs to continue to learn from the past to remain effective in the future. 
High management flexibility and rapid response. Emergency evacuation from buildings in extreme events essentially requires emergent leaders and self-organizing groups, since it is highly likely that one or more fire protection systems and/or egress paths will be compromised, and successful evacuation will require quick decisions and group support [26]. There are examples of this from the World Trade Center [21], and allowing for such behavior in evacuation planning for very tall buildings is worth further exploration.

Exploit fully existing response capabilities. There are many requirements for evacuation and emergency response planning for buildings [26, 32], as well as guidance documents for building owners/managers [33] and emergency responders [34]. To be effective, the linkages and synergies between these need to be evaluated and integrated into a comprehensive approach [35]. A critical issue, which has gotten recent attention, is system interoperability; that is, having the technical capability for communication systems of different emergency responders to work as part of a single system when needed.

Sustain and build anticipatory and response capabilities. Although planning for extreme fire events can benefit from adaptive approaches, there are fundamental needs that must be addressed in the planning, such as fire fighting water, fire fighting and emergency rescue equipment, communication, manpower needs and so forth. Operating in an adaptive environment does not mean one discards the existing capabilities and replaces them, but builds upon the existing capabilities to increase response effectiveness. Looking at new building features and technologies, such as fire fighter elevators, internal wireless communications systems (repeaters), internal cameras for situational awareness, and other such measures are examples of building on existing emergency response capabilities.

\section{Features}

Real-time monitoring. Real-time monitoring of events is one area where significant advancement is possible for responding to fire events in buildings. Although there is currently a wide range of building management systems and sensors, fire detection and suppression systems and sensors, and security systems and sensors in use, the systems are often unconnected and not providing as much real-time data decisionmaking as is possible. As we move forward, technologies such as 'sensor-nets' and various emergent information and communication technology can play a large role in adaptive emergency response approaches by allowing real time data to be available to building occupants, fire wardens, and emergency responders, which can help to create more adaptable evacuation and response.

Contingency planning. As noted above, numerous standards and guidelines regarding contingency planning for fire exist, such as NFPA 1600, Standard on Disaster/Emergency Management and Business Continuity Programs [31]. The need for such planning will increase and will have to become more adaptive in the future. Multiple decision tools are needed in this environment.

Dense communication and information environments. A fire emergency is often characterized by a large number of items happening simultaneously, and communication of information can be transmitted in various ways. In most cases the building's fire alarm system is used. Depending on the building, its function and local code requirements, the fire alarm system may involve voice communication with speakers, or horns, bells or other sounding devices for audible notification. In addition, strobe lights are often provided to assist with visual means of communication in many cases. Non-emergency public address systems can also be used as a means to manually alert occupants. These, however, are not typically designed to the same degree of reliability, nor meet spacing/audible/intelligible requirements throughout a facility as may be required for a fire alarm system. More and more, the use of pagers, email/text messaging, telephones (mobile and land-based), computers and other devices are also being used as supplemental notification means. Mass notification systems are also starting to be used for emergency notification. The aim of mass notification systems is to get important emergency messages to all people simultaneously; and may also involve combinations of the above.

From both a design and an operational perspective, the availability, accessibility, reliability, compatibility and intelligibility of communications equipment must be considered. Availability relates to a communication system, such as a public address system, being installed and operational at the time of need. Accessibility and reliability are components related to gaining access to the microphone(s) and control equipment, and the ability of the system to remain operational during an event. For example, a public address system intended for use during an emergency should be connected to the emergency power circuit or other standby power to ensure that communication with patrons is possible during a power failure. 
Robustness requirements and acceptability with local authorities should also be considered if these types of systems are to be used for emergency purposes. Where two-way radios are used by staff and emergency responders, the compatibility between communications equipment should be verified, and if not compatible, should be addressed as part of a communications plan. Intelligibility relates to the ability for the voice message to be clear and understandable given the environment.

Open management systems. Building fire safety design is characterized by open codes- and standardsmaking processes, where proposed changes are made available for public comment. This allows for the learning and adaptation processes discussed above to be realized in the regulatory development process.

Uncertainty and error acknowledgement. More and more, fire protection regulations are taking on riskinformed performance-based approaches [30,36]. Such approaches are adaptive in the sense that each building is required to be assessed for a wide range of potential fire scenarios, and fire protection systems and strategies are selected based on a combination of factors, including occupant risk factors, a wide range of possible fire scenarios, and expected emergency response. This approach requires identification and treatment of uncertainty and variability as part of process.

Bottom-up and top-down planning. Building fire safety regulation, design and emergency planning is characterized by positive information flow from many sources, including research, regulatory developers, engineers, and emergency responders. This diversity of stakeholder involvement results in effective learning and adaptation throughout the spectrum from regulatory development to emergency response.

\section{CONCLUSIONS}

Application of the CRS adaptive management criteria to challenges of fire regulation, protection and emergency response planning for buildings indicates that adaptive approaches may be helpful for identifying better regulatory approaches, mitigation design concepts, evacuation strategies and emergency response requirements. Several aspects of the fire problem, including high uncertainty about the fire event and occupant response, indicate that systems and strategies which can adapt to the specifics of a fire event may provide an increased level of safety without incurring significantly more cost. If more adaptive approaches are applied, results will include broadening stakeholder input, which will help to increase the level of education regarding fire events and the role that various agents play, as well as better informing stakeholders about performance expectations of buildings and emergency responders. In addition, application of adaptive, scenario-based analysis allows for a broader understanding of possible fire impacts, so even if the worst-case events are not protected against, critical information about the potential impacts of such events will be known and can be available for contingency and continuity planning post event. During events, assuming that appropriate detection, reporting, communication, and information systems are implemented, the feedback available (situational awareness) can facilitate adaptation by those evacuating a building, as well as those responding to the emergency, to result in better mitigation and response, and ultimately in decreased life loss, damage and financial impact. Although undertaken at a high level, this fire study case highlights several of the challenges associated with regulatory, mitigation and emergency response planning for highly uncertain events and indicates that regulatory development, mitigation planning, and emergency response and evacuation planning can benefit from adaptive management concepts. Going forward, additional research and testing is needed to further refine the application of the CRS criteria for identifying hazard events appropriate to adaptive management approaches and for developing recommended changes to regulations, mitigation strategies and response planning. Better integration of decision tools and models, in concert with the overall decision, planning, and implementation frameworks, are areas that can enhance this planning leading to reduced risks and greater reduction in loss of life from these unforeseen events.

\section{ACKNOWLEDGEMENTS}

The authors would like to extend their sincere appreciation to all members of the Clark University Center for Risk and Security for their research into adaptive management, development of the CRS adaptive management criteria, and testing of the CRS criteria on various types of disaster and emergency response scenarios. We would also like to thank the reviewers for insightful comments which will be helpful in furthering research into the applicability of adaptive management concepts to fire safety regulation, mitigation, and emergency response planning. 


\section{REFERENCES}

[1] McConnell, A., and Drennan, L., 2006. "Mission Impossible? Planning and Preparing for Crisis” Journal of Contingencies and Crisis Management, 14 (2), 59-70. doi:10.1111/j.1468-5973.2006.00482.x

[2] Holland, J. H., 1975. “Adaptation in Natural and Artificial Systems,” University of Michigan Press, Ann Arbor.

[3] Holland, J. H., 1995. "Hidden Order: How Adaptation Builds Complexity,” New York: AddisonWesley.

[4] Comfort, L., 2002. "Rethinking Security: Organizational Fragility in Extreme Events,” Public Administration Review, Vol. 62, Special Edition, September 2002.

[5] Plsek, P., Lindberg, C. and Zimmerman, B., 1997. Some Emerging Principles for Managing in Complex Adaptive Systems, working paper, November 25, 1997.

[6] Dooley, K., 1997. "A Complex Adaptive Systems Model of Organization Change," Nonlinear Dynamics, Psychology, \& Life Science, Vol. 1, No. 1, p. 69-97.

[7] Lee, Kai N., 1993. Compass and Gyroscope. Integrating science and politics for the environment. Washington, D.C.: Island Press.

[8] Bennett, J. and Lawrence, P., 2002. “Adaptive Management Framework for Catchment and Coastal Management and Decision Making,” Proceedings of Coast to Coast 2002, accessed at http://www.coastal.crc.org.au/coast2coast2002/proceedings/Theme2/Adaptive-managementframework.pdf

[9] Johnson, Barry L., 1999. The Role of Adaptive Management as an Operational Approach for Resource Management Agencies. Conservation Ecology 3 ( 2 ): 8.

[10] Wise, C. R., 2006. "Organizing for Homeland Security after Katrina: Is Adaptive Management What's Missing?” Public Administration Review 66 (3), pp. 302-318. doi:10.1111/j.1540$\underline{6210.2006 .00587 . x}$

[11] Walters, Carl, 1986. Adaptive Resource Management.

[12] Carley, K.M., 2002. "Inhibiting Adaptation,” Proceedings of the 2002 Command and Control Research and Technology Symposium. Conference held in Naval Postgraduate School, Monterey, CA. Evidence Based Research, Vienna, VA.

[13] Comfort, L., 2002. "Managing Intergovernmental Responses to Terrorism and Other Extreme Events,” Publius: The Journal of Federalism, Vol. 32, No. 4.

[14] Perry, R.W. and Lindell, M.K., 2003. "Understanding Citizen Response to Disasters with Implications for Terrorism,” Journal of Contingencies and Crisis Management, Vol. 11 No. 2.

[15] Meacham, B.J. and Sarkis, J., 2008. “Adaptive Management in Disaster and Emergency Response Planning," submitted for publication in Assavapokee, T., Editor, Handbook on Emergency Evacuation and Disaster Management, Auerbach (scheduled for publication in 2008).

[16] Funtowicz, S.O. and Ravetz, J.R., 1985. "Three Types of Risk Assessment,” in Whipple and Covello, eds., Risk Analysis in the Private Sector, Plenum Press, NY.

[17] Stern, P.C. and Fineburg, H.V., eds., 1996. Understanding Risk: Informing Decisions in a Democratic Society, National Academy Press, Washington, DC.

[18] Meacham, B.J., 2004. "Understanding Risk: Quantification, Perception and Characterization,” JFPE, Vol. 14, No. 3, pp.199-228. doi:10.1177/1042391504042454

[19] Meacham, B.J., 2003. "Risk and Data Needs for Performance-based Codes," in the Workshop Papers of the Report, Making the Nation Safe from Fire - A Path Forward in Research, National Academies Press, (papers on CD). 
[20] Meacham, B.J., 2001. "Characterizing Risk for Performance-Based Building Regulations,” Proceedings of the International Conference on Safety and Risk in Engineering, International Association for Bridge and Structural Engineering, Zurich, Switzerland, pp.525-530.

[21] Collapse of the World Trade Center Towers. Final Report. Federal Building and Fire Safety Investigation of the World Trade Center Disaster, NIST NCSTAR 1, National Institute of Standards and Technology, Gaithersburg, MD, 298 p., September 2005.

[22] Report of the Technical Investigation of the Station Nightclub Fire, NIST NCSTAR 2: Volume 1; National Institute of Standards and Technology, Gaithersburg, MD, 246 p., June 2005.

[23] Ahrens, M., 2006. Fire loss in the United States During 2006, National Fire Protection Association, Quincy, MA.

[24] Aguirre, B. E., Wenger, D. and Vigo, G., 1998. “A Test of Emergent Norm Theory of Collective Behavior.” Sociological Forum, Vol. 13, No. 2: 301-320. doi:10.1023/A:1022145900928

[25] Santos, and Aguirre, B., 2005. “A Critical Review of Emergency Evacuation Simulation Models,” in Kulogowski, E. and Peacock, R., editors, NIST Workshop on Building Occupant Movement during Fire Emergencies, NIST Special Publication 1032, Gaithersburg, MD: National Institute of Standards and Technology, March 2005.

[26] Tubbs, J. and Meacham, B.J. 2007. Egress Design Solutions: A Guide to Evacuation and Crowd Management Planning, John Wiley \& Sons, NY.

[27] Bryan, J., 2002. "Behavioral Response to Fire and Smoke," Chapter 3-12, SFPE Handbook of Fire Protection Engineering, ${ }^{\text {rd }}$ Edition, National Fire Protection Association, Quincy, MA.

[28] Proulx, G., Fahy, R.F. and Walker, A., 2004. Analysis of First-Person Accounts from Survivors of the World Trade Center Evacuation on September 11, 2001, NRC Client Report B-4534, National Research Council, Ottawa, Ontario, Canada.

[29] Meacham, B.J., 2008. “A Risk-Informed Performance-Based Approach to Building Regulation,” Proceedings of the $7^{\text {th }}$ International Conference on Performance-Based Codes and Fire Safety Design Methods, SFPE, Bethesda, MD.

[30] Meacham, B.J., 2006. "Extreme Event Mitigation through Risk-Informed Performance-Based Analysis and Design," Chapter 2, Extreme Event Mitigation in Buildings: Analysis and Design, Meacham and Johann, Eds., National Fire Protection Association, Quincy, MA.

[31] NFPA 1600, Standard on Disaster/Emergency Management and Business Continuity Programs, National Fire Protection Association, Quincy, MA.

[32] NFPA 101, Life Safety Code@, National Fire Protection Association, Quincy, MA.

[33] Meacham, B.J. and Johann, M. Eds., 2006. Extreme Event Mitigation in Buildings: Analysis and Design, National Fire Protection Association, Quincy, MA.

[34] National Incident Management System, FEMA 501, US Department of Homeland Security.

[35] Groner, N.E., 2004. "Integrating Physical Systems and Human Behavior Using Codes and Standards Requirements for Building Evacuation,” Proceedings of Workshop on Building Occupant Movement During Fire Emergencies, edited by Peacock, R.D., and Kuligowski, E.D., June 10-11, 2004, National Institute of Standards and Technology, Washington, D.C., pp. 6-12.

[36] Meacham, B.J., 2007. The Use of Risk Concepts in Regulation - Report of the IRCC Workshop, San Francisco, CA, 17-18 October 2006, Arup and IRCC, www.ircc.gov.au. 